\title{
BIOMARKERS TO ASSESS LIVER FUNCTION IN VARIOUS TYPES OF LIVER DISEASES
}

\author{
Pradeep G ${ }^{1}$, Vikram B ${ }^{2}$, Sharma DVHS ${ }^{3}$ \\ ${ }^{I}$ Tutor, Department of Biochemistry, Navodaya Medical College and Hospital, Raichur, Karnataka State, India. \\ ${ }^{2}$ Tutor, Department of Biochemistry, Koppal Institute of Medical Sciences and Hospital, Koppal, Karnataka \\ ${ }^{3}$ Professor and HOD, Department of Biochemistry, SVS Medical College and Hospital,
} Mahabubnagar District, Telangana State, India.

\begin{abstract}
Background: It is estimated that liver diseases are among the top ten killer diseases in India, causing deaths every year. Besides, there are those who suffered from chronic liver problems needing recurrent hospitalization and prolonged medical attention, which leaves them physically, mentally, emotionally and financially devastated. Methodology: The study included $(\mathrm{n}=80)$ various liver disease patients admitted to the General Medicine department and controls $(n=20)$ subjects were having normal health within the age group of 30-55 years. Serum levels of bilirubin, Aspartate Transaminase, Alanine Amino Transferase, Alkaline Phosphatase and Gamma Glutamyl Transferase parameters were studied among the subjects suffering from cirrhosis, alcoholic liver disease, viral hepatitis, obstructive jaundice type of liver diseases. Result: The results of this study showed that the increase in serum levels of Bilirubin, AST, ALT, ALP and GGT in various types of liver diseases i.e Obstructive jaundice, Cirrhosis of the liver, Viral hepatitis, Alcoholic Liver disease when compared with controls. Conclusion: Biochemistry laboratory investigations i.e. Liver Function Test (LFT) are a simple, easy measure of tools which can early diagnose the various types of liver diseases.
\end{abstract}

Keywords: Liver diseases; Liver Bio-markers; Liver Function Test.

\section{INTRODUCTION}

The liver functions primarily as a metabolic organ and is in constant exposure to dietary and microbial antigens [1]. Liver disease includes many diverse conditions, diseases and infections that affect the morphology and function of the liver, alterations in the liver function test (LFT) easily observable manifestations of liver disease [2].

Cirrhosis is the final stage of chronic liver disease. It results in distortion of the hepatic architecture by fibrosis, and the formation of regenerative nodules [3]. It is the result of progressive liver fibrosis caused by chronic liver diseases, including viral hepatitis, alcoholic liver disease, non-alcoholic steatohepatitis (NASH), autoimmune liver disease, and genetic disorders, amongst others [4].

Alcohol is also a frequent co-factor in patients with other type of liver disease such as hepatitis $\mathrm{C}$ virus (HCV) infection where it accelerates hepatic fibrosis [5]. Owing to various susceptibility factors, individuals with long-term heavy alcohol use remain at risk for advanced liver disease with alcoholic steatohepatitis (ASH), cirrhosis, and hepatocellular carcinoma (HCC) [6]. Alcohol abuse or alcohol dependence is not synonymous

$\begin{array}{ll} & \text { DOI: } 10.31878 / \text { ijcbr.2019.52.06 } \\ & \end{array}$

with clinically important ALD, as only about 10-20\% of chronic heavy drinkers develop severe forms such as AH or cirrhosis [7].

Hepatitis means "inflammation of the liver". Five types of viruses can cause viral hepatitis. Of these, the most common cause of infection is one of four viruses: hepatitis A, B, C or E. Hepatitis D, also referred to as hepatitis D virus, or hepatitis delta virus (HDV) is considered to be a sub viral satellite because it can propagate only in the presence of the hepatitis B virus (HBV). All or any of these viruses can cause an acute disease, with symptoms lasting several weeks, including yellowing of the skin and eyes (jaundice), dark urine, extreme fatigue, nausea, vomiting and abdominal pain. It can take several months to a year to feel fit again. Easily contracted in many ways, from drinking water to casual contact or sexual intercourse, this debilitating disease poses a risk to everyone [8].

Obstructive jaundice results from biliary obstruction, which is blockage of any duct that carries bile from liver to gallbladder and then to small intestine [9]. The most common causes of obstructive jaundice are cholelithiasis, structures of the biliary tract, cholangio-carcinoma, carcinoma of pancreas, pancreatitis, parasites and primary sclerosing cholangitis [10]. The prevalence of gallbladder and bile duct stones rises with age [11]. Up to $90 \%$ of patients with pancreatic head carcinoma exhibit the signs and symptoms of obstructive jaundice at the time of presentation [12].

Correspondence: Pradeep G, Tutor, Department of Biochemistry, Navodaya Medical College and Hospital, Raichur, Karnataka State, India. Email: pradeepreddygundumalla@gmail.com 


\section{MATERIAL AND METHODOLOGY}

Study design: An observational case control study

Ethics approval: The study protocol was approved by the institutional ethics committee. A written informed consent was obtained from each subject.

Research place: The study was conducted in the Department of Biochemistry association with Department of General Medicine, at SVS Medical College and Hospital, Mahabubnagar District, Telangana State, India.

Sample size: One hundred were included in the study Inclusion criteria: The study included $(n=80)$ various liver disease patients admitted to General Medicine Department. Patient age group of 35 to 55 years. In these $(n=20)$ were diagnosed as cirrhosis, $(n=20)$ were alcoholic liver disease, $(n=20)$ were viral hepatitis, $(n=20)$ obstructive jaundice. Controls $(n=20)$ subjects were hospital staff having normal health within the age group of 30-55 years.

Exclusion criteria: Patients suffering with other chronic liver diseases, cardiac problems, on tuberculosis treatment and higher antibiotics on long term

The data on personal history, regarding the onset of the disease, alcohol consumption and treatment history for liver disease were collected through standard questionnaire.

The present study was taken up to estimate serum levels in Bilirubin, AST, ALT, ALP and Gamma Glutamyl Transferase (GGT) parameters among the subjects suffering with various liver diseases.

\section{Methodology:}

Sample collection: Blood samples were collected from both cases and controls. $5 \mathrm{ml}$ of random blood withdrawn from a cubital vein into blood tubes. The serum was then separated from the cells by centrifugation at $3000 \mathrm{rpm}$ for $10 \mathrm{~min}$.
In the serum estimated Bilirubin by Jendrassik Groff ${ }^{n} \mathrm{~s}$ method, AST by UV kinetic method, ALT by UV kinetic method, ALP by PNP AMP kinetic method, and GGT by Colorimetric method, by using Siemens-ADVIA Chemistry XPT system Auto analyzer.

And reference ranges are Total Bilirubin: 0.2-1.0 mg/dl, Aspartate Transaminase: 4-45 IU/L, Alanine Transaminase: 3-40 IU/L, Alkaline Phosphatase: 25-80 IU/L, Gamma Glutamyl Transferase:10-45 U/L

Statistical analysis: The descriptive results were expressed as Mean and Standard deviation. Significance of the difference between the patient and control groups observed was assessed by using the student t-test.

\section{RESULTS}

The results of this study showed that the increase in serum levels of Bilirubin, AST, ALT, ALP and GGT in various types of liver diseases i.e Cirrhosis of liver, Alcoholic Liver Disease, Viral hepatitis, Obstructive jaundice when compared with control serum levels. (Table 1)

\section{DISCUSSION}

The present study involves estimation of parameters relating to inflammatory process, defense mechanism of the individual and also the products for damage caused to the cells in liver disease. The estimated parameters of or enzymes are Bilirubin, AST, ALT, ALP and GGT related to hepatocellular damage.

The present study includes 80 subjects who are diagnosis to be having liver disease due to some reasons or others. The above estimated parameters were compared with the same parameters obtained from control group comprised of 20 individuals.

Table 1: Comparison of liver function test with serum enzymes in different types of liver disease patients with controls

\begin{tabular}{l|l|l|l|l|l|l}
\hline $\begin{array}{l}\text { LFT } \\
\text { Parameters }\end{array}$ & Controls & $\begin{array}{l}\text { Cirrhosis of } \\
\text { Liver }\end{array}$ & $\begin{array}{l}\text { Alcoholic Liver } \\
\text { Disease }\end{array}$ & $\begin{array}{l}\text { Viral } \\
\text { Hepatitis }\end{array}$ & $\begin{array}{l}\text { Obstructive } \\
\text { Jaundice }\end{array}$ & p-Value \\
\hline $\begin{array}{l}\text { Bilirubin } \\
(\mathrm{mg} / \mathrm{dL})\end{array}$ & $0.6 \pm 0.15$ & $4.015 \pm 2.03$ & $6.23 \pm 2.4$ & $5.12 \pm 2.26$ & $11.2 \pm 3.34$ & $<0.001$ \\
\hline AST (IU/L) & $21.05 \pm 4.5$ & $95.0 \pm 9.7$ & $239.2 \pm 15.4$ & $290.0 \pm 17.1$ & $91.9 \pm 9.5$ & $<0.001$ \\
\hline ALT (IU/L) & $24 \pm 4.8$ & $98.5 \pm 9.9$ & $152.0 \pm 12.3$ & $499.3 \pm 22.3$ & $96.35 \pm 9.81$ & $<0.001$ \\
\hline ALP (IU/L) & $118.2 \pm 10.8$ & $151.15 \pm 12.3$ & $222.15 \pm 17.5$ & $183.85 \pm 13.6$ & $678.45 \pm 26$ & $<0.001$ \\
\hline GGT (U/L) & $23 \pm 4.7$ & -- & $480.0 \pm 21.9$ & -- & - & $<0.001$ \\
\hline
\end{tabular}

p-Value $\leq 0.001$ was considered statistically highly significant.

The serum Bilirubin levels are increased when compared with control. The p-Value $(<0.001)$ is comparatively highly significant when compared with controls.

The serum AST, ALT, ALP levels are increased and p-Value $(<0.001)$ is comparatively highly significant when compared with controls.

The p-value of CGT $(<0.001)$ is comparatively highly significant when compared with controls. 
The various enzymatic parameters included in LFT's are Serum Bilirubin, AST, ALT, ALP and GGT. The present study it is observed that obstructive Jaundice shows a highest rise in Serum Bilirubin levels, followed by Alcoholic Liver Disease, Viral Hepatitis, Cirrhosis of liver. Respectively. Viral Hepatitis shows a highest rise in AST levels, followed by Alcoholic Liver Disease, Cirrhosis of liver and Obstructive Jaundice, respectively. The obstructive jaundice shows a highest rise in ALP levels followed by Alcoholic Liver Disease.

The present study has shown that significant increased serum levels of Bilirubin, AST, ALT, ALP and GGT in obstructive Jaundice, viral Hepatitis, cirrhosis of Liver, alcoholic Liver Disease in cases when compared with controls.

In earlier studies shown that ALT exceeds AST in toxic hepatitis, viral hepatitis, chronic active hepatitis and cholestatic hepatitis by Rosalki SB et.al [13]

Previous studies shown that increased bilirubin, ALP levels in obstructive jaundice [14]. Earlier studies shown that levels of Aspartate Aminotransferase (AST) and Alanine Aminotransferase (ALT) are moderately elevated in cirrhosis; however, normal Aminotransferase levels do not exclude cirrhosis. Alkaline phosphatase is usually mildly elevated in cirrhosis [15]

In earlier studies shown the increase of GGT in alcoholic liver disease done by Wu. A. et al [16], Selinger M. J. et al [17]

The results of the present study also shown coincides with earlier studies in obstructive jaundice, viral hepatitis, cirrhosis of liver, alcoholic liver disease respectively [13-17]

\section{CONCLUSION}

Most of the liver disease are asymptomatic. A simple and easy biochemistry laboratory investigation i.e. Liver Function Test (LFT) can early diagnose a disease in a single visit of a patient and conformed to ultrasonography.

Suggestion: Thus, early diagnosis, treatment can halt the progression of liver diseases, modifiable risk factors like alcohol can be withdrawn by life style modifications.

Acknowledgment: We, authors are thankful to management of SVS Medical College and Hospital, for their support. We, authors are thankful to subjects for their cooperation to finish this study.

Conflict of Interest: Declared none

\section{REFERENCES}

[1] Nemeth E, Barid AW, O'Farrelly CO. Microanatomy of the liver immune system. Semin Immunopathol 2009;31:333-43
[2] DiMarino AJ. Sleisenger \& Fordtran's Gastrointestinal and Liver Disease, 8th Edition. Philadelphia: WB Saunders Co; 2006.

[3] Anthony PP. The morphology of cirrhosis. Recommendations on definition, nomenclature, and classification by a working group sponsored by the World Health Organization. J Clin Pathol. 1978;31 (5):395-414.

[4] Buti M. Long-term clinical outcomes in cirrhotic chronic hepatitis B patients treated with tenofovir disoproxil fumarate for up to 5 years. Hepatol Int. 2015;9(2):243-50

[5] Lackner C, Spindelboeck W, Haybaeck J. Histological parameters and alcohol abstinence determine long-term prognosis in patients with alcoholic liver disease. J Hepatol 2017;66:610 -8 .

[6] Morgan TR, Mandayam S, Jamal MM. Alcohol and hepatocellular carcinoma. Gastroenterology 2004;127:S87- 96

[7] Gao B, Bataller R. Alcoholic liver disease: pathogenesis and new therapeutic targets. Gastroenterology $2011 ; 141: 1572-85$

[8] Thacker SB. Historical development. In: Principles and practice of public health surveillance. Edited by S. Teutsch and RE Churchill. Oxford: Oxford University Press, 2000.

[9] Khurram M, Durrani AA, Hasan Z, Butt Au, Ashfaq S. Endoscopic retrograde cholangiopancreatographic evaluation of patients with obstructive jaundice. J Coll Physicians Surg Pak. 2003;13:325 $-8$

[10] Vargus CG, Astete BM. Endoscopic Retrograde Cholangiopancreatography (ERCP): Experience in 902 procedures at the Endoscopic Digestive Center of Arzobipolayza Hospital. Rev Gastroenterol Peru. 1997;17:222-230.

[11] Obana T, Fujita N, Noda Y, Kobayashi G, Ito K, Horaguchi J, et al. Efficacy and safety of therapeutic ERCP for the elderly with choledocholithiasis: Comparison with younger patients. Inter Med. 2010; 49: 1935-41

[12] Distler M, Kersting S, Rückert F, Dobrowolski F, Miehlke S, Grützmann R, et al. Palliative treatment of obstructive jaundice in patients with carcinoma of the pancreatic head or distal biliary tree. Endoscopic stent placement vs. hepaticojejunostomy. JOP J Pancreas. 2010; 11:568-74

[13] Rosalki SB, Mcintyre N. Biochemical investigations in the management of liver disease. Oxford textbook of clinical hepatology, 2nd ed. New York; Oxford university press, 1999; 503-21 
[14] Sunanda, Ramesh M, Sangeeta S, Prabhakarrao B. Study of biochemical markers in jaundice: our experience Int J Biol Med Res. 2012;3(1):1365-68

[15] European Association for the Study of the Liver. EASL Clinical Practice Guidelines: Management of cholestatic liver diseases. J Hepatol. 2009;51 (2): $237-67$

[16] Wu A, Slavin G, Levi AJ. Elevated serum GGT and histo-logical liver damage in alcoholism. Am. J. Gastroenterol. 1976;65:318-23

[17] Selinger MJ. GGT activity in liver disease. Clin Chim. Acta. 1982;125(3): 283-90 